\title{
BBB (Bermain, Belajar, Berkarya) Strategi Meningkatkan Kepercayaan Diri Siswa Beragama Buddha Di Sekolah Dasar Negeri 2 Plososari Patean Kendal
}

\author{
Widi Astiyono \\ Sekolah Dasar Negeri 2 Plososari Patean Kendal Jawa Tengah \\ widiastiyono@gmail.com
}

\section{Article History}

accepted 01/12/2020

approved 01/01/2021

published 01/03/2021

\begin{abstract}
SD Negeri 2 Plososari is located in Plososari, Patean District, Kendal Regency, Central Java. Plososari is a village located in a mountainous area. Students need to be provided with good character to support the learning process and foster self-confidence. The BBB strategy as an alternative way to solve problems in order increasing the self-confidence of Buddhist students based on the idea that students' self-confidence lies deep in the students themselves. The operational stages of implementing BBB consist of the following steps: (1) Observing the subject matter for Finding Story Ideas. (2) Playing socio dramas, films, being a cameraman. (3) Creating short films for instructional videos. (4) Uploading works in to YouTube Channel so the work can be watched by the netizens. The results achieved from the chosen strategy are selfconfidence, opportunities for improvisation, creation of short films and recognized by the wider community. Based on the results of the implementation of BBB so far, it is recommended: (1) principals need to encourage teachers to be more active in improving self-competence, (2) teachers must be able to integrate with information technology as a support for innovation and work, (3) in innovating and working, teachers need to involve their students directly so that students have confidence as part of the innovation and work done by the teacher.
\end{abstract}

Keywords: play, learning, work, socio drama, short films, buddha, self-confidence.

\begin{abstract}
Abstrak
SD Negeri 2 Plososari terletak di Desa Plososari Kecamatan Patean Kabupaten Kendal Jawa Tengah. Desa Plososari merupakan desa yang terletak di daerah pegunungan. Siswa perlu dibekali dengan karakter yang baik, untuk mendukung proses pembelajaran, dan menumbuhkan kepercayaan dirinya. Strategi BBB sebagai alternative untuk memecahkan masalah dalam meningkatkan kepercayaan diri siswa-swi beragama Buddha di landasi pemikiran bahwa kepercayaan diri siswa terletak pada siswa-siswi itu sendiri. Tahapan operasional penerapan BBB terdiri atas beberapa langkah-langkah sebagai berikut: (1) Mencermati materi pelajaran untuk Mencari Ide Cerita. (2) Bermain sosio drama, film, menjadi cameramen. (3) Mewujudkan karya film pendek untuk video pembelajaran. (4) Menguploud Karya ke Chanel YouTubeagar karya bisa di tonton oleh masyarakat luas. Hasil yang Dicapai dari Strategi yang Dipilih adalah Kepercayaan diri, Peluang berimprovisasi, Terciptanya Karya Film Pendek dan Dikenal oleh Masyarakat luas Berdasarkan hasil dari penerapan BBB selama ini, maka direkomendasikan: (1) kepala sekolah perlu mendorong guru-guru untuk lebih giat dalam meningkatkan kompetensi diri, (2) guru harus mampu berintegrasi dengan teknologi informasi sebagai penunjang dalam berinovasi dan berkarya, (3) dalam berinovasi dan berkarya, guru perlu melibatkan siswanya secara langsung agar siswa punya kepercayaan diri sebagai bagian dari inovasi dan karya yang dilakukan oleh guru.
\end{abstract}

Kata kunci: bermain, belajar, berkarya, sosio drama, film pendek, buddha, percaya diri.

Social, Humanities, and Education Studies (SHEs): Conference Series https://jurnal.uns.ac.id/shes

p-ISSN 2620-9284

e-ISSN 2620-9292 


\section{PENDAHULUAN}

SD Negeri 2 Plososari terletak di Desa Plososari Kecamatan Patean Kabupaten Kendal Jawa Tengah. Desa Plososari merupakan desa yang terletak di daerah pegunungan. Di Desa Plososari Kecamatan Patean terdapat empat sekolah dasar dan salah satunya adalah SD Negeri 2 Plososari Patean. Pendidikan Agama Buddha merupakan bagian proses pembelajaran di SD Negeri 2 Plososari dan menjadi salah satu bagian dari tujuan untuk mencapai visi SD Negeri 2 Plososari Patean.

Siswa perlu dibekali dengan karakter yang baik, untuk mendukung proses pembelajaran, dan menumbuhkan kepercayaan dirinya. Siswa akan lebih mudah menerima materi pelajaran jika mereka dilibatkan secara langsung dan merasakan manfaatnya. Dalam hal peningkatan kepercayaan diri dan pemahaman tentang materi pelajaran, guru dapat melakukan inovasi dan berkreatifitas. Kenyataannya, selama ini siswa di SD Negeri 2 Plososari yang merupakan sekolah pinggiran (baca pegunungan) dinilai kurang dalam hal kepercayaan diri dan pemahaman materi pelajaran dibandingkan dengan sekolah di daerah perkotaan.

Berdasarkan hasil wawancara dengan Bapak Samidi selaku ketua komite sekolah ternyata masyarakat menganggap bahwa anak-anak perlu ditingkatkan karakternya terutama kepercayaan diri. Hal ini karena anak-anak menganggap mereka adalah anak gunung atau anak desa. Persepsi ini menjadi sebuah tantangan sekolah dalam mewujudkan visi dan misinya. Kondisi ini membutuhkan strategi yang komperhensif untuk mengatasi permasalahan agar siswa-siswi SD Negeri 2 Plososari memiliki keinginan untuk meningkatkan kepercayaan diri dan semangat dalam memahami materi pelajaran dalam kehidupan mereka, khususnya siswa-siswi beragama Buddha yang selama ini merupakan kelompok minoritas di masyarakat maupun di sekolah.

Siswa-siswi beragama Buddha di SD Negeri 2 Plososari jarang tampil untuk menunjukkan potensi dirinya, misalnya tampil di depan kelas bermain drama, menyanyi dan pidato. Kurangnya kesempatan beraktualisasi diri di lingkungan sekolah dapat menghambat kesempatan siswa untuk lebih maju dan berprestasi. Berdasarkan pengalaman mengajar di sekolah ini mulai tahun 1999 sampai 2013, penulis masih melaksanakan pembelajaran secara konvensional dan hasilnya belum sesuai harapan. Sebuah inovasi kecil tahun 2014 dengan melibatkan siswa untuk membuat film pendek untuk video pembelajaran sesuai dengan materi pelajaran ternyata membuat anak lebih bersemangat.

Sebuah strategi pembelajaran yang sederhana ini ternyata membuat siswa meningkat kepercayaan diri dan pemahamannya tentang materi pelajaran Pendidikan Agama Buddha di SD Negeri 2 Plososari. Berdasarkan pengalaman ini penulis tertarik untuk menyusun peper dalam bentuk best practice dengan judul BBB (bermain, belajar, dan berkarya) strategi meningkatkan kepercayaan diri siswa beragama buddha di SD Negeri 2 Plososari Kendal yang pada akhirnya bermuara pada pencapaian pembelajaran yang lebih optimal.

Berdasarkan uraian pada latar belakang masalah memperlihatkan bahwa SDN 2 Pososari menghadapi permasalahan untuk itu perlu dicarikan solusinya. Guna memberi panduan dalam pemecahan masalah, permasalahan dirumuskan; 1) Bagaimana penerapan BBB (bermain, belajar, dan berkarya) strategi meningkatkan kepercayaan diri siswa beragama buddha di SD Negeri 2 Plososari Kendal? ; 2) Bagaimana hasil penerapan BBB (bermain, belajar, dan berkarya) strategi meningkatkan kepercayaan diri siswa beragama buddha di SD Negeri 2 Plososari Kendal?. Tujuan dari penulisan ini adalah Untuk mengetahui penerapan BBB (bermain, belajar, dan berkarya) strategi meningkatkan kepercayaan diri siswa beragama buddha di SD Negeri 2 Plososari Kendal dan mengetahui hasil penerapan BBB (bermain, belajar, dan berkarya) strategi meningkatkan kepercayaan diri siswa beragama buddha di SD Negeri 2 Plososari Kendal. 


\section{HASIL DAN PEMBAHASAN}

Strategi BBB sebagai alternative untuk memecahkan masalah dalam meningkatkan kepercayaan diri siswa-swi beragama Buddha di landasi pemikiran bahwa kepercayaan diri siswa terletak pada siswa-siswi itu sendiri. Untuk itu guru perlu membimbing dan memberdayakan potensi siswa-siswi tersebut melalui proses pembelajaran yang inovatif dan kreatif dengan strategi BBB; bermain, belajar dan berkarya. Strategi ini dilakukan melalui beberapa tahap yaitu: (1) mencermati materi pelajaran untuk mencari ide cerita, (2) bermain sosio drama, film, menjadi cameramen, (3) mewujukan karya dengan membuat film pendek dan (4) menguploud karya ke chanel YouTube.

Tahapan operasional penerapan BBB terdiri atas beberapa langkah-langkah sebagai berikut:

1. Mencermati materi pelajaran untuk Mencari Ide Cerita. Dalam proses pembelajaran siswa Bersama-sama mencermati pelajaran kemudian berdiskusi untuk mencetuskan ide cerita. Ide cerita kemudian di kembangkan kedalam synopsis, scenario cerita dan storyboard. Sebagai pedoman untuk bermain sosio drama yang pada akhirnya diwujudkan menjadi film pendek.

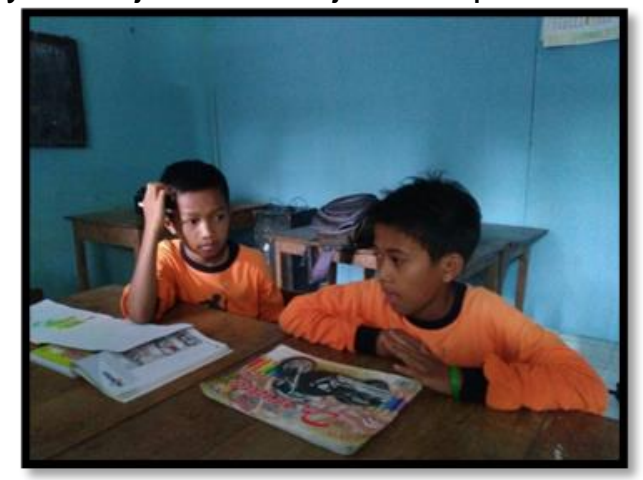

\section{Gambar 1. Siswa sedang berdiskusi untuk mencetuskan ide cerita}

2. Bermain sosio drama, film, menjadi cameramen. Kegiatan ini memberi kesempatan untuk berimprovisasi dalam bermain serta belajar menjadi cameramen. Slswa, selain bermain dalam sosio drama/film juga di arahkan untuk belajar menjadi cameramen. Mereka diberi kebebasn untuk berimprovisasi, baik saat berperan dalam film atau menjadi cameramen, namun tetap diarahkan sesuai dengan scenario dan storyboard yang telah di persiapkan.

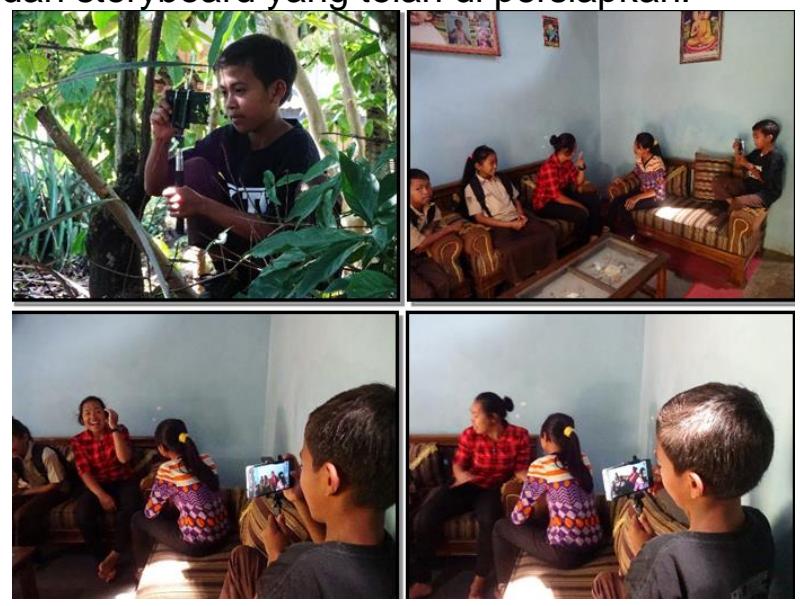

Gambar 2. Siswa sedang bermain sosio drama yang dijadikan film pendek dan sekaligus berperan sebagai kameramen. 
3. Mewujudkan karya film pendek untuk video pembelajaran. Langkah ini merupakan hasil dari mencetuskan ide yang dikembangkan dalam synopsis cerita, scenario cerita dan storyboard, kemudian diwujudkan dalam film pendek video pembelajaran dengan memberikan kesepatan kepada siswa untuk berkreasi dalam bidang pembuatan video pembelajaran dengan guru sebagai fasilitator dalam proses pembelajaran yang multi pembelajaran. Disebut multi pembelajaran karena dalam proses pembuatan video pembelajaran ini siswa terlibat secara langsung dan bisa berperan sebagai penulis cerita, cameramen, sutradara, sekaligus pemain dalam film pendek tersebut.

4. Menguploud Karya ke Chanel YouTube. Strategi ini merupakan penghargaan yang diterima oleh siswa sebagai akibat dari aktifitas pembelajaran melalui pembuatan film pendek. Apresiasi berupa mempublikasikan film pendek tersebut seluasluasnya melalui jaringan internet (YouTube) agar karya bisa di tontonoleh masyarakat luas.

Hasil yang Dicapai dari Strategi yang Dipilih

1. Kepercayaan diri

Sebelum strategi BBB, siswa-siswi beragama Buddha kurang percaya diri untuk tampil di depan public. Setelah strategi BBB, mereka lebih percaya diri.

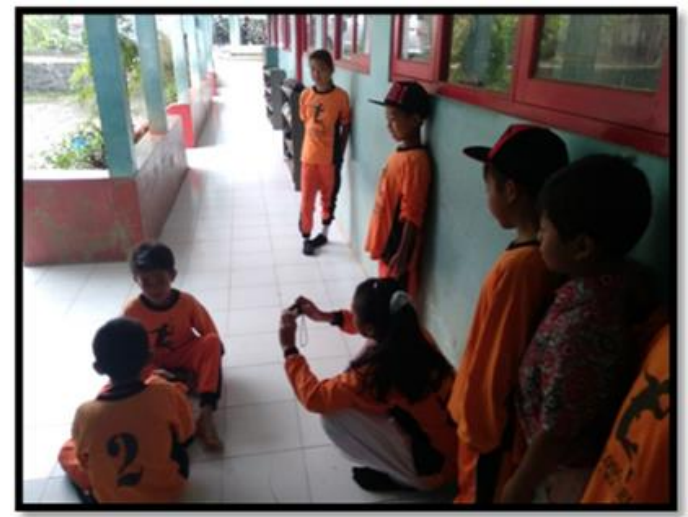

Gambar 3. Saat shooting, ditonton oleh teman-temannya, tetap percaya diri dan tidak lagi malu

2. Peluang berimprovisasi

Sebelum penerapan BBB, pembelajaran cenderung teacher centered dan monoton sehingga siswa pasif, dan belum mampu berimprovisasi. Setelah penerapan strategi BBB mereka lebih proaktif dan mampu berimprovisasi.

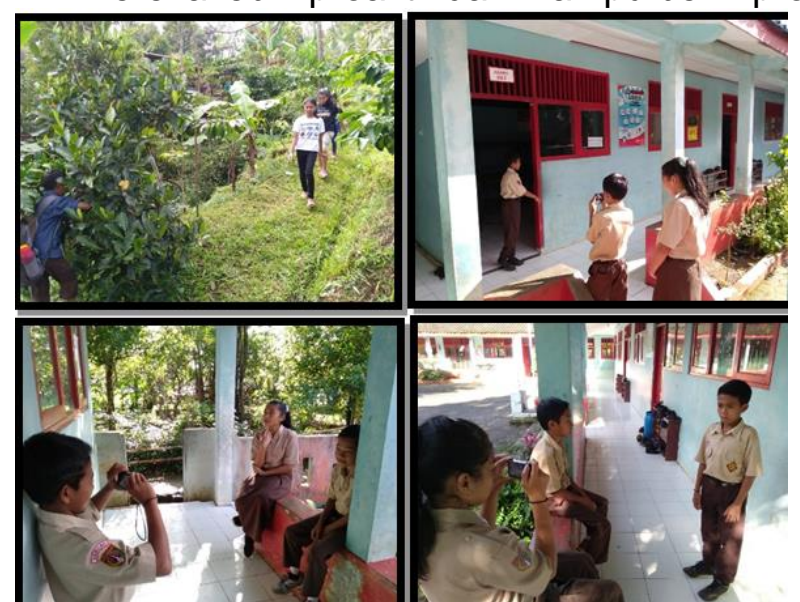

Gambar 4. Bermprovisasi dalam pengambilan gambar 
3. Terciptanya Karya Film Pendek

Sebelum penerapan strategi BBB, guru dan siswa belum mampu mewujudkan karya inovatif berupa film pendek untuk video pembelajaran. Setelah penerapan strategi BBB guru bersama siswa mampu mewujudkan karya-karya berupa film pendek untuk video pembelajaran.

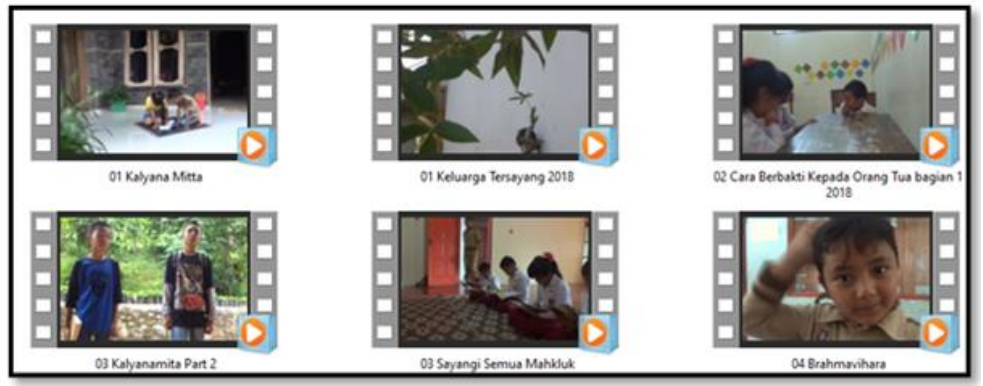

Gambar 5. Beberapa judul karya video pembelajaran film pendek

4. Dikenal oleh Masyarakat luas

Sebelum penerapan strategi BBB guru dan siswa belum memiliki karya berupa film pendek yang bisa di posting atau di tayangkan di YouTube, sehingga tidak dikenal oleh masyarakat luas. Setelah penerapan strategi BBB, guru dan siswa bisa menguploud karya-karyanya di YouTube, sehingga menjadi di kenal oleh masyarakat. Selain itu, apresiasi untuk siswa, ketika penulis mendapat tugas sebagai narasumber dengan materi pembuatan media pembelajaran, film karya Bersama siswa tersebut selalu diputar dan di pertontonkan kepada peserta workshop sebagai salah satu inspirasi.

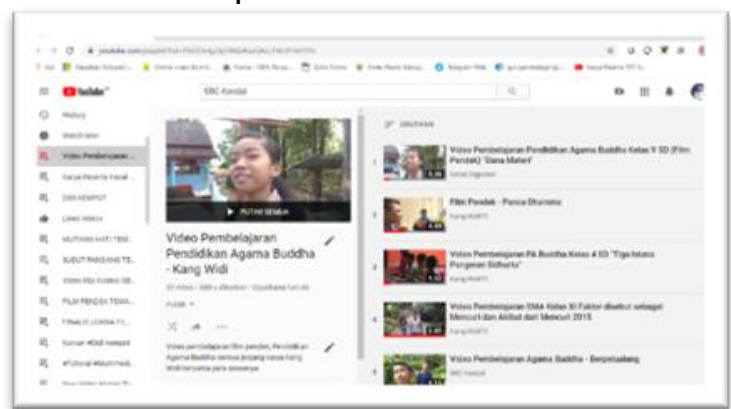

\section{Gambar 6. Playlis Video pembelajaran yang sudah di uploud di YouTube}

Secara umum kendala yang dhadapi dalam menerapkan strategi BBB untuk meningkatkan kepercayaan diri siswa relative kecil, karena walaupun sarana dan prasarana di sekolah belum sepenuhnya ada, penulis dengan mandiri melengkapi dan memenuhi kebutuhan sarana prasarana tersebut untuk kepentingan penembangan video pembelajaran, mampu menguasai aplikasi editing audio dan video. Salah satu hal yang dilakukan untuk menunjang sarana dan prasarana tersebut, penulis juga secara mandiri mendirikan Studio Rekaman di salah satu ruangan dirumah.
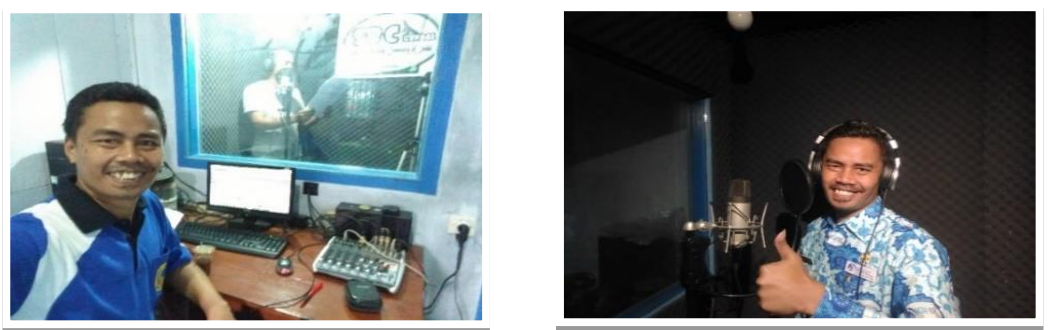

Gambar 7. Penulis di studio rekaman yang dibuat secara mandiri 
Beberapa factor pendukung sebagai penguat penerapan strategi BBB di antaranya: (1) kepala sekolah dan guru lainnya selalu memberi support, (2) siswayang tidak begitu banyak mudah untuk diarahkan, (3) jaringan internet sudah terjangkau, sehingga untuk menguploud hasil karya ke YouTube tidak mengalamikesulitan yang berarti.

Untuk meningkatkan kepercayaan diri siswa hendaknya di arahkan kepada keterlibatan siswa secara langsung dalam proses bembelajaran dan pembuatan media pembelajaran khususnya video pembelajaran. Pembuatan media pembelajaran dalam bentuk video pembelajaran ini dikembangkan sebagai bentuk pengembangan diri guru dalam berinovasi dan berkarya sehinga akan memberikan kantribusi dalam peningkatan kompetensi guru dan peningkatan kualitas Pendidikan.

Kepala sekolah secara konsisten hendaknya selalu memberikan motvasi kepada para guru terutama mereka yang kurang mendukung inovasi dan kreatifitas dalam rangka peningkatan kompetensi guru dan kualitas Pendidikan.

\section{SIMPULAN}

Pengalaman menerapkan strategi BBB yang telah diuraikan pada bab-bab sebelumnya dapat disimpulkan bahwa:

1. Penerapan strategi BBB di SD Negeri 2 Plososari dilakukan melalui 4 program pokok yaitu: (1) Mencermati materi pelajaran untuk Mencari Ide Cerita, (2) Bermain sosio drama, film, menjadi cameramen, (3) Mewujudkan karya film pendek untuk video pembelajaran, (4) Menguploud Karya ke Chanel YouTube.

2. Hasil dan Dampak dari penerapan strategi BBB di SD Negeri 2 Plososari Kecamatan Petean Kabupaten Kendal adalah Penerapan strategi BBB di SD Negeri 2 Plososari yaitu: (1) terbentuknya kepercayaan diri diri siswa. (2) adanya peluang berimprovisasi dalam belajar. (3) terwujudan karya-karya video pembelajaran film pendek yang meibatan siswa, dan (4) adanya perolehan apresiasi yang berupa perasaan senang, bangga, dan di kenal oleh masyarakat luas melalui karya-karya yang di uploud di chanel YouTube. Konsistensi penulis dalam mengembangkan video pembelajaran ini mendapat apresiasi berupa penghargaan Anugerah Bupati Kendal Award, Anugerah ASN 2018 dan 2019 serta Anugerah Guru Indonesia.

Berdasarkan hasil dari penerapan BBB selama ini, maka direkomendasikan: (1) kepala sekolah perlu mendorong guru-guru untuk lebih giat dalam meningkatkan kompetensi diri, (2) guru harus mampu berintegrasi dengan teknologi informasi sebagai penunjang dalam berinovasi dan berkarya, (3) dalam berinovasi dan berkarya, guru perlu melibatkan siswanya secara langsung agar siswa punya kepercayaan diri sebagai bagian dari inovasi dan karya yang dilakukan oleh guru.

DAFTAR PUSTAKA

Angutara Nikaya I (The Book Of The Gradual Sayings Vol.I). 1989. London: PaliText Society.

Angutara Nikaya III (The Book Of The Gradual Sayings Vol.I). 1986. London: Pali Text Society

Angutara Nikaya IV (The Book Of The Gradual Sayings Vol.I). 1986 London: Pali Text society

Angutara Nikaya V (The Book Of The Gradual Sayings Vol.I). 1986. London: Pali Text Society Society

Arikunto, Suharsimi. 2006. Prosedur Penelitian Suatu Pendekatan Praktik. Jakarta: Rineka Cipta.

Arikunto, Suharsimi. 2014. Prosedur Penelitian Suatu Pendekatan Praktik. Jakarta: Rineka Cipta.

Arikunto, Suharsimi. 2015. Penelitian Tindakan kelas. Jakarta: Bumi Aksara 
Dhammananda, Sri. 2004. Keyakinan Umat Buddha. Jakarta: Pustaka Karaniya.

Arzyad, Azhar. 2011. Media Pembelajaran. Jakarta:PT. Rajagrafindo Persada Dananjaya, Utomo. 2012. Media Pembelajaran Aktif. Bandung: Penerbit NUANSA Dhammapada (The Word Of The Doctrine) 2000. Translated. K.R. Norman. Oxford: The Pali Text Society.

Digha Nikaya (Dialogue Of The Buddha) Vol II. Terjemahan David, Rhys. 1979. London: The Pali Text Society.

Majjhima Nikaya II (The Middle Length Saying). 1970. Transled.I.B Horner. Oxford. The Pali Text Society.

Majjhima Nikayal (The Middle Length Saying vol.1). 1989. Terjemahan .I.B Horner. London. The Pali Text Society.

Majjhima Nikaya III (The Middle Length Saying). 1970. Transled.I.B Horner. Oxford. The Pali Text Society.

Mukti, Krishananda Wijaya. 2003. Wacana Buddha Dharma. Jakarta: Ekayana Buddhist Centre.

Panjika. 2004. Kamus Umum Buddha Dhamma. Jakarta: Tri Sattva Buddhis Center.

Sardiman, AM.2006. Interaksidan MotivasiBelajar Mengajar. Jakarta: PT. Raja Grafindo Persada

Arikunto. Suharsini.2014. Prosedur Penelitian. Jakarta: Bumi Aksara

Sutta Nipata (The Group Of Discourses). Terjemahan Norman, Horner, I.B \&

Walpola Rahula.1984.London: The Pali Teks Society

The Group Of Discipline. Terjemahan Bhikkhu Nyanamoli. 1982. London: The Pali Teks Society http://kbbi.web.id/ (diakses 22 Februari 2020). http://www.psychologymania.com/2012/06/pengertian-bermain-peran roleplay.html (diakses 22 Februari 2020)

http://belajarpsikologi.com/macam-macam-metode-pembelajaran/ (diakses Februari 2016)

http://belajarpsikologi.com/pengertian-kepercayaan-diri/ (diakses 9 februari 2016

http://kbbi.web.id/ (diakses 10 Februari 2020)

http://www.psychologymania.com/2012/06/pengertian-bermain-peran-roleplay.html (diakses 10 Februari 2020)

Dimyati,Dr,Mudjiyon0, Drs. 2009. Belajar dan pembelajaran. Jakarta: Rineka Cipta.

Dharmananda, Sri. 2004. Masalah dan Tanggung Jawab. Jakarta: Dian Dharma.

Djaali. 2008. Psikologi Belajar. Jakarta: Rineka Cipta.

Djamarah ,Syaiful Bahri. 2008. Psikologi Belajar. Jakarta: PT. Rineka Cipta.

Hadi, Sutrisno. 2001. Statistik. Yogyakarta: Andi Offseet.

Hamalik, Oemar, Dr, Prof. 2004. Proses Belajar Mengajar. Jakarta: PT. Bumi Aksara Julius.C,Ramapak. 2000. Kamus Besar Bahasa Indonesia. Jakarta: Balai Pustaka.

Mukti, Krishananda Wijaya. 2003. Wacana Buddha Dharma. Jakarta: Ekayana Buddhist Centre.

Nursito. 2002. Peningkatan Prestasi Belajar Menengah. Jakarta: Insan Cendekia.

Sardiman, AM.2006. Interaksi dan Motivasi Belajar Mengajar. Jakarta: PT. Raja Grafindo Persada

Slameto. 2003. Belajar dan Faktor Yang Mempengaruhinya. Jakarta: PT. Rineka Cipta.

Sugiyono. 2008. Metode Penelitian Kuantitatif, kualitatif dan R\&D. Bandung: Alfabet.

Sugiyono. 2008. Statistik Untuk Penelitian Kuantitatif, Kualitatif Dan R \& D. Bandung: Alfabeta

Sutta Nipata (The Group Of Discourses).Terjemahan Norman, Horner, I.B \& Walpola Rahula. 1984. London: The Pali Teks Society.

Slavin, E. Robert. 2011. Psikologio pendidikan Teori dan Praktik. Jakarta: PT.Indeks. Syah, Muhibbin. 2006. Psikologi Pendidikan. Bandung: PT. Remaja Rosdakarya.

Mulyasa. 2003. Kurikulum Berbasis Kompetensi. Bandung: PT. Remaja Rosdakarya. Nazir, Moh. 2005. Metode Penelitian. Bogor: Ghalia Indonesia. 
SHEs: Conference Series 4 (2) (2021) 63-70

Mahathera, Vidhudhammabhon. 1989:9. Buddha Cakkhu Asadha 2533. Jakarta: Dhammacakka Jaya

Kompri. 2016. Motivasi Pembelajaran, Perspektif Guru dan Siswa. Jakarta: Remaja Rosdakarya 